\title{
Perindopril for improving cardiovascular events
}

\author{
This article was published in the following Dove Press journal: \\ Vascular Health and Risk Management \\ 30 August 2014 \\ Number of times this article has been viewed
}

\section{James J DiNicolantonio James H O'Keefe}

Department of Preventive Cardiology, Saint Luke's Mid America Heart Institute, Kansas City, MO, USA
Correspondence: James J DiNicolantonio Saint Luke's Mid America Heart Institute, 440I Wornall Road 600

Kansas City, MO 64III, USA

Tel + I 8I693| I883

Email jjdinicol@gmail.com

\section{Dear editor}

In a recent review in Vascular Health and Risk Management Wang et al state that "In mainly placebo-controlled cardiovascular (CV)-outcome studies in patients with hypertension, $\mathrm{CV}$ benefits with perindopril were associated with large reductions in BP." However, perindopril in the European Trial on Reduction of Cardiac Events With Perindopril in Stable Coronary Artery Disease (EUROPA) study significantly reduced major cardiovascular events despite a small reduction (approximately $4 \mathrm{mmHg}$ ) in systolic blood pressure from baseline., ${ }^{2,3}$ Additionally, the average baseline blood pressure in the EUROPA was just 137/82 $\mathrm{mmHg}$, and in those without hypertension, perindopril still provided a $20 \%$ reduction in the combined endpoint of cardiovascular death, myocardial infarction, and cardiac arrest. ${ }^{4,5} \mathrm{In}$ fact, patients receiving perindopril with a baseline systolic blood pressure of $<120 \mathrm{mmHg}$ had the greatest reduction in the primary event. ${ }^{6}$

PERindopril-Thrombosis, InflammatioN, Endothelial dysfunction and Neurohormonal activation Trial (PERTINENT), a sub study of EUROPA, also showed that perindopril improves endothelial function, which the authors concluded may have provided the benefit and not blood pressure reduction per se. ${ }^{7}$ Thus, the notion that perindopril is only effective in hypertensive patients, and only when large reductions in blood pressure occur, is not supported by the literature.

The authors go on to state that,

The beyond-BP-lowering CV-protective benefits of telmisartan were demonstrated in the active-controlled ONTARGET (ONgoing Telmisartan Alone and in combination with Ramipril Global Endpoint Trial) trial.

However, ambulatory and night-time systolic blood pressure was significantly lower with telmisartan versus ramipril $\left(-3.1 \mathrm{mmHg}\right.$ and $-4.1 \mathrm{mmHg}$, respectively). ${ }^{8}$ Despite this fact, telmisartan was not superior to ramipril in reducing cardiovascular events or mortality. It is also surprising that telmisartan did not significantly reduce stroke compared to ramipril, especially considering that this endpoint is strictly dependent on blood pressure reduction. For instance, in the Anglo-Scandinavian Cardiac Outcomes Trial-Blood Pressure Lowering Arm (ASCOT-BPLA), with only a $2.7 \mathrm{mmHg}$ difference, perindopril/amlodipine significantly reduced all-cause mortality $(-11 \%)$ and stroke $(-23 \%)$, supporting the beyond-blood pressure-lowering benefits of this particular combination (Table 1). ${ }^{9}$ Additionally, in ONTARGET, ramipril was dosed in 
Table I Clinical trials testing perindopril and telmisartan

\begin{tabular}{|c|c|c|c|c|c|c|}
\hline Trial & Treatment & Comparator & $\begin{array}{l}\text { Baseline } \\
\text { SBP }\end{array}$ & $\begin{array}{l}\text { SBP difference } \\
\text { between arms }\end{array}$ & $\begin{array}{l}\text { Total mortality } \\
\text { benefit }\end{array}$ & $\mathbf{C l}$ \\
\hline \multicolumn{7}{|l|}{ Perindopril } \\
\hline ADVANCE & Perindopril (+ indapamide) & Placebo & $145 \mathrm{mmHg}$ & $-5.6 \mathrm{mmHg}$ & $-14 \%$ & $(-25 ;-2)$ \\
\hline ASCOT & Perindopril (+ amlodipine) & Atenolol + thiazide & $164 \mathrm{mmHg}$ & $-2.7 \mathrm{mmHg}$ & $-11 \%$ & $(-9 ;-1)$ \\
\hline EUROPA & Perindopril & Placebo & $137 \mathrm{mmHg}$ & $-5 \mathrm{mmHg}$ & $-11 \%$ & $(-22 ;+2)$ \\
\hline \multicolumn{7}{|l|}{ Telmisartan } \\
\hline ONTARGET & Telmisartan (+ ramipril) & Ramipril & $142 \mathrm{mmHg}$ & $-2.4 \mathrm{mmHg}$ & $+7 \%$ & $(-2 ;+16)$ \\
\hline PROFESS & Telmisartan & Placebo & $144 \mathrm{mmHg}$ & $-4 \mathrm{mmHg}$ & $+3 \%$ & $(-7 ;+14)$ \\
\hline TRANSCEND & Telmisartan & Placebo & $141 \mathrm{mmHg}$ & $-4 \mathrm{mmHg}$ & $+5 \%$ & $(-9 ;+22)$ \\
\hline
\end{tabular}

Notes: Data from. 2,9,13,14,21,41

Abbreviations: ASCOT, Anglo-Scandinavian Cardiac Outcomes Trial; EUROPA, European Trial on Reduction of Cardiac Events With Perindopril in Stable Coronary Artery Disease; ONTARGET, ONgoing Telmisartan Alone and in combination with Ramipril Global Endpoint Trial; PROFESS, Prevention Regimen for Effectively Avoiding Second Strokes; TRANSCEND, Telmisartan Randomized Assessment Study in ACE intolerant; Cl, confidence interval; SBP, systolic blood pressure.

the morning, which resulted in a clear reduction in morning blood pressure, and during the first 6 hours of the dosing interval, in favor of telmisartan. ${ }^{8}$ It was well known from the prospective, randomized investigation of the safety and efficacy of telmisartan versus ramipril using ambulatory blood pressure monitoring (PRISMA)-I and -II trials, before the onset of ONTARGET, that telmisartan provides significantly greater blood pressure reductions versus ramipril, particularly during the last 6 hours of the dosing interval, yet ramipril was dosed once a day, in the morning. ${ }^{10}$ Thus, we are left to wonder whether this was strategic, especially when previous large cardiovascular outcomes trials testing ramipril such as the Heart Outcomes Prevention Evaluation (HOPE) trial gave ramipril once daily at night and Acute Infarction Ramipril Efficacy (AIRE) gave ramipril twice daily. ${ }^{11,12}$ The most likely reason for this was to cover the early morning blood pressure surge and the loss of ramipril's antihypertensive effect during the end of the dosing interval. Thus, ONTARGET did not dose ramipril optimally, which may have lessened any potential advantages of ramipril in the setting.

With respect to blood pressure-independent benefits of telmisartan, in Telmisartan Randomized Assessment Study in ACE intolerant (TRANSCEND), telmisartan as compared to placebo in patients with cardiovascular disease, or high-risk diabetes and without heart failure, who were intolerant to angiotensin-converting enzyme inhibitors (ACE-Is), did not reduce cardiovascular death, myocardial infarction, stroke or hospitalization for heart failure, despite a significant reduction in blood pressure. ${ }^{13}$ Additionally, in patients soon after an ischemic stroke, telmisartan (continued for 2.5 years) did not significantly lower the rate of recurrent stroke, major cardiovascular events, or diabetes, despite a significant reduction in blood pressure. ${ }^{14}$ Lastly, telmisartan was compared over a period of 4 years to the diuretic amiloride, with each of the two agents being combined with amlodipine. Despite similar reductions in blood pressure, telmisartan was not better than amiloride on any single cardiovascular endpoint or mortality. ${ }^{15}$ The aforementioned data do not support the notion that "telmisartan provides beyond-blood pressurelowering benefits." However, perindopril was found to have beyond-blood pressure-lowering benefits in the Diabetes Artery Perindopril Hypertension Normalization Excess sTiffness (DAPHNET) study. ${ }^{16}$ This trial, testing perindopril in hypertensive patients with type 2 diabetes, showed that perindopril $8 \mathrm{mg}$, as opposed to $4 \mathrm{mg}$, significantly improves carotid distensibility, despite similar reductions in ambulatory blood pressure. ${ }^{16}$ The Blood Pressure Lowering Treatment Trialists' Collaboration (BPLTTC) also showed that ACEinhibitors, but not angiotensin receptor blockers (ARBs), have blood-pressure-independent effects on the risk of major coronary disease events. ${ }^{17}$ Additionally, a meta-regression by the BPLTTC also showed risk reductions of $28 \%$ in stroke, $22 \%$ in major cardiovascular events, $20 \%$ in cardiovascular death, $20 \%$ in coronary heart disease, $18 \%$ in heart failure, and $12 \%$ in all-cause mortality with ACE-Is versus placebo. ${ }^{18}$ These data provide strong evidence that ACE-Is, particularly perindopril, provides cardiovascular protection beyond blood pressure lowering.

Another point that we take issue with is,

ACE inhibitors and ARBs have been shown in head-to-

head comparison trials to have comparable $\mathrm{CV}$ protective effects.

In Diabetics Exposed to Telmisartan and Enalapril (DETAIL), telmisartan (80 mg daily) was directly compared to enalapril (20 $\mathrm{mg}$ daily) in a randomized, multicenter, double-blind, 5 year study. ${ }^{19}$ This trial was composed of 250 subjects with type 2 diabetes and early nephropathy. Despite a larger reduction in systolic blood pressure with telmisartan $(-6.9 \mathrm{mmHg})$ as compared to enalapril $(-2.9 \mathrm{mmHg})$, there 
was a less marked deterioration in the glomerular filtration rate, although not statistically so, with enalapril $(-14.9 \mathrm{~mL}$ per minute) versus telmisartan $(-17.9 \mathrm{~mL}$ per minute). Additionally, there were numerically more cases of congestive heart failure (9 versus 7 ) and non-fatal myocardial infarctions (9 versus 6) on telmisartan versus enalapril. Thus, despite greater blood pressure control, telmisartan does not produce better cardiovascular protection or renoprotection compared to enalapril. This is intriguing as perindopril, but not enalapril, has been shown to reduce cardiovascular events in patients with documented coronary heart disease. ${ }^{2,20}$

In regards to the ONTARGET trial, myocardial infarctions were numerically lower on ramipril $(4.8 \%)$ versus telmisartan $(5.2 \%)$ as were hospitalizations for heart failure $\left(4.1 \%\right.$ versus $4.6 \%$, respectively). ${ }^{21}$ Thus, ONTARGET does not necessarily prove that telmisartan is equal to ramipril, especially when blood pressure was significantly lower on telmisartan. Additionally, ramipril significantly slowed the decline in estimated glomerular filtration rate versus telmisartan $(P<0.0001)$, despite telmisartan leading to significantly greater reductions in ambulatory blood pressure. ${ }^{22}$ These results do not support a "comparable cardiovascular protection" with ARBs versus ACE-Is, especially when blood pressure control was not comparable. In ONTARGET, telmisartan was not compared against placebo, and a placebo-controlled trial is the gold-standard to test if a medication provides cardiovascular protection. These data are unfortunately lacking with telmisartan. Indeed, to our knowledge, telmisartan has no data versus placebo showing a significant reduction in all-cause mortality or myocardial infarctions. In fact, we are unaware of a single trial testing any ARB that has showed a significant reduction in all-cause mortality or myocardial infarctions versus placebo or active therapy. This is supported by several meta-analyses showing that ACE-inhibitors but not ARBs reduce all-cause mortality and myocardial infarctions. ${ }^{23-27}$

In a direct comparison trial in hypertensive patients, perindopril, but not telmisartan, significantly improved endothelial function (eg, decreased von Willebrand factor), provided anti-platelet effects (eg, decreased soluble P-selectin and soluble glycoprotein V), and produced profibrinolytic activity (eg, decrease in plasminogen activator inhibitor type 1 and tissue type plasminogen activator antigens). ${ }^{28}$ It was concluded that perindopril, but not telmisartan, provides vasculoprotective, anti-platelet and profibrinolytic effects. These pleiotropic effects may be important for perindopril's ability to reduce cardiovascular morbidity and mortality. This is supported by another trial, where only perindopril, but not telmisartan, improved conduit artery endothelium-dependent vasodilation. ${ }^{29}$ Thus, head-to-head trials do not support equivalent cardiovascular effects with perindopril versus telmisartan.

In regards to "ARBs having fewer adverse effects and better patient compliance,"' perindopril has demonstrated extremely low rates of cough in several large randomized trials. ${ }^{2,30}$ In Perindopril and Remodeling in Elderly with Acute Myocardial Infarction (PREAMI), Perindopril pROtection aGainst REcurrent Stroke Study, (PROGRESS), and EUROPA, perindopril was associated with a low rate of withdrawal due to cough $\left(1.6 \%, 2.2 \%\right.$, and $2.7 \%$, respective)..$^{2,30,31}$ In ONTARGET, cough was significantly increased with ramipril versus telmisartan $(P<0.001)$. Importantly, other ACE-Is have shown a higher incidence of cough as compared to perindopril. ${ }^{32,33}$ In ONTARGET, telmisartan significantly increased hypotensive symptoms compared to ramipril $(P<0.001)$. Both PROGRESS and EUROPA have shown excellent tolerability with perindopril, with low rates of withdrawals due to hypotension (2.1\% and $1.0 \%$, respectively). ${ }^{2,31}$ Additionally, perindopril has also shown less first-dose hypotension compared to other ACE-Is, ${ }^{34-36}$ suggesting that ARBs may not necessarily have fewer adverse events and better tolerability compared to ACE-Is, especially in regards to hypotension. Thus, the purported notion that telmisartan is better tolerated than ACE-Is, is not clear-cut, especially in regards to perindopril.

Regarding comparison trials for blood pressure lowering, in the only head-to-head randomized study comparing full-dose therapy of the two agents, perindopril $(10 \mathrm{mg})$ as compared to telmisartan $(80 \mathrm{mg})$ significantly reduced 24 hour systolic blood pressure $(-22$ versus $-15 \mathrm{mmHg}$ ) and central aortic blood pressure (30\% versus 14\%). ${ }^{37}$ Central and ambulatory blood pressure levels are well recognized as better prognostic indicators compared to brachial blood pressure measurements. ${ }^{38,39}$ This may partly explain the disparate effects seen with perindopril and telmisartan on cardiovascular outcomes. These data are consistent with a meta-analysis showing that ARBs have a very shallow doseresponse effect on ambulatory blood pressure. ${ }^{40}$

In summary, as compared to placebo, perindopril but not telmisartan has been shown to reduce major cardiovascular events. A broad amount of data support the blood-pressure independent benefits of ACE-Is, especially in regards to perindopril. Numerous meta-analyses now confirm that ACE-Is, but not ARBs, reduce the rate of all-cause mortality and myocardial infarctions. As compared to other ACE-Is, perindopril has been shown to have fewer adverse 
side effects, including lower rates of cough and first-dose hypotension. Due to perindopril's long history of cardiovascular protection and enhanced tolerability, it should be a first-choice ACE-I. Moreover, ACE-Is, as compared to ARBs, should be considered first-line antihypertensives, with telmisartan being no exception.

\section{Disclosure}

Dr DiNicolantonio received honorarium from Servier for preparation of this manuscript. Dr O'Keefe declares no conflicts of interest. Servier provided Table 1.

\section{References}

1. Wang JG, Pimenta E, Chwallek F. Comparative review of the blood pressure-lowering and cardiovascular benefits of telmisartan and perindopril. Vasc Health Risk Manag. 2014;10:189-200.

2. Fox KM; EURopean trial On reduction of cardiac events with Perindopril in stable coronary Artery disease Investigators. Efficacy of perindopril in reduction of cardiovascular events among patients with stable coronary artery disease: randomised, double-blind, placebo-controlled, multicentre trial (the EUROPA study). Lancet. 2003;362(9386):782-788.

3. Ferrari R, Fox K. Insight into the mode of action of ACE inhibition in coronary artery disease: the ultimate 'EUROPA' story. Drugs. 2009;69(3):265-277.

4. DiNicolantonio JJ, Lavie CJ, O'Keefe JH. Not All AngiotensinConverting Enzyme Inhibitors Are Equal: Focus on Ramipril and Perindopril. Postgrad Med. 2013;125(4):154-168.

5. Aseeva OA. Coversyl: At the core of cardiovascular disease prevention and treatment. Medicographia. 2009;31(1):69-76.

6. Remme WJ, Deckers JW, Fox KM, Ferrari R, Bertrand M, Simoons ML; EUROPA Investigators. Secondary prevention of coronary disease with ACE inhibition-does blood pressure reduction with perindopril explain the benefits in EUROPA? Cardiovasc Drugs Ther. 2009;23(2): 161-170.

7. Ceconi C, Fox KM, Remme WJ, et al. ACE inhibition with perindopril and endothelial function. Results of a substudy of the EUROPA study: PERTINENT. Cardiovasc Res. 2007;73(1):237-246.

8. Mancia G, Parati G, Bilo G, et al. Ambulatory blood pressure values in the Ongoing Telmisartan Alone and in Combination with Ramipril Global Endpoint Trial (ONTARGET). Hypertension. 2012;60(6):1400-1406.

9. Poulter NR, Wedel H, Dahlöf B, et al. Role of blood pressure and other variables in the differential cardiovascular event rates noted in the Anglo-Scandinavian Cardiac Outcomes Trial-Blood Pressure Lowering Arm (ASCOT-BPLA). Lancet. 2005;366(9489):907-913.

10. Williams B, Lacourcière Y, Schumacher H, Gosse P, Neutel JM. Antihypertensive efficacy of telmisartan vs ramipril over the 24-h dosing period, including the critical early morning hours: a pooled analysis of the PRISMA I and II randomized trials. J Hum Hypertens. 2009;23(9): 610-619.

11. Yusuf S, Sleight P, Pogue J, Bosch J, Davies R, Dagenais G. Effects of an angiotensin-converting-enzyme inhibitor, ramipril, on cardiovascular events in high-risk patients. The Heart Outcomes Prevention Evaluation Study Investigators. N Engl J Med. 2000;342(3):145-153.

12. [No authors listed]. Effect of ramipril on mortality and morbidity of survivors of acute myocardial infarction with clinical evidence of heart failure. The Acute Infarction Ramipril Efficacy (AIRE) Study Investigators. Lancet. 1993;342(8875):821-828.

13. Telmisartan Randomised AssessmeNt Study in ACE iNtolerant subjects with cardiovascular Disease (TRANSCEND) Investigators, Yusuf S, Teo K, et al. Effects of the angiotensin-receptor blocker telmisartan on cardiovascular events in high-risk patients intolerant to angiotensinconverting enzyme inhibitors: a randomised controlled trial. Lancet. 2008;372(9644):1174-1183.
14. Yusuf S, Diener HC, Sacco RL, et al. Telmisartan to prevent recurrent stroke and cardiovascular events. N Engl J Med. 2008;359(12):1225-1237.

15. Wang W, Ma LY, Liu MB, et al. Effects of amlodipine plus telmisartan or amlodipine plus amiloride regimen on blood pressure control in hypertensive patients: preliminary report of Chinese Hypertension Intervention Efficacy (CHIEF) trial. ESH congress, oral presentation, Milan 2013. Cardiotimes; 2013. Available from: http://www.cardiotimes. com/?s=chief. Accessed July 31, 2014.

16. Tropeano AI, Boutouyrie P, Pannier B, et al. Brachial pressureindependent reduction in carotid stiffness after long-term angiotensinconverting enzyme inhibition in diabetic hypertensives. Hypertension. 2006;48(1):80-86.

17. Blood Pressure Lowering Treatment Trialists' Collaboration, Turnbull F, Neal B, Pfeffer M, et al. Blood pressure-dependent and independent effects of agents that inhibit the renin-angiotensin system. J Hypertens. 2007;25(5):951-958.

18. Turnbull F, Blood Pressure Lowering Treatment Trialists' Collaboration. Effects of different blood-pressure-lowering regimens on major cardiovascular events: results of prospectively-designed overviews of randomised trials. Lancet. 2003;362(9395):1527-1535.

19. Barnett AH, Bain SC, Bouter P, et al. Angiotensin-receptor blockade versus converting-enzyme inhibition in type 2 diabetes and nephropathy. N Engl J Med. 2004;351(19):1952-1961.

20. Nissen SE, Tuzcu EM, Libby P. Effect of antihypertensive agents on cardiovascular events in patients with coronary disease and normal blood pressure: the CAMELOT study: a randomized controlled trial. JAMA. 2004;292(18):2217-2225.

21. ONTARGET Investigators, Yusuf $\mathrm{S}$, Teo KK, et al. Telmisartan, ramipril, or both in patients at high risk for vascular events. $N$ Engl $J$ Med. 2008;358(15):1547-1559.

22. Mann JF, Schmieder RE, McQueen M, et al. Renal outcomes with telmisartan, ramipril, or both, in people at high vascular risk (the ONTARGET study): a multicentre, randomised, double-blind, controlled trial. Lancet. 2008;372(9638):547-553.

23. Strauss MH, Hall AS. Angiotensin Receptor Blockers May Increase Risk of Myocardial Infarction Unraveling the ARB-MI Paradox. Circulation. 2006;114(8):838-854.

24. van Vark LC, Bertrand M, Akkerhuis KM, et al. Angiotensinconverting enzyme inhibitors reduce mortality in hypertension: a meta-analysis of randomized clinical trials of renin-angiotensinaldosterone system inhibitors involving 158,998 patients. Eur Heart $J$. 2012;33(16):2088-2097.

25. Cheng J, Zhang W, Zhang X, et al. Effect of angiotensin-converting enzyme inhibitors and angiotensin II receptor blockers on all-cause mortality, cardiovascular deaths, and cardiovascular events in patients with diabetes mellitus: a meta-analysis. JAMA Intern Med. 2014;174(5): 773-785.

26. Wu HY, Huang JW, Lin HJ, et al. Comparative effectiveness of reninangiotensin system blockers and other antihypertensive drugs in patients with diabetes: systematic review and bayesian network meta-analysis. BMJ. 2013;347:f6008.

27. Savarese G, Costanzo P, Cleland JG, et al. A meta-analysis reporting effects of angiotensin-converting enzyme inhibitors and angiotensin receptor blockers in patients without heart failure. $\mathrm{J} \mathrm{Am} \mathrm{Coll} \mathrm{Cardiol}$. 2013;61(2):131-142.

28. Remková A, Kratochvíl'ová H, Durina J. Impact of the therapy by renin-angiotensin system targeting antihypertensive agents perindopril versus telmisartan on prothrombotic state in essential hypertension. J Hum Hypertens. 2008;22(5):338-345.

29. Ghiadoni L, Magagna A, Versari D, et al. Different effect of antihypertensive drugs on conduit artery endothelial function. Hypertension. 2003;41(6):1281-1286.

30. Ferrari R; Perindopril and Remodeling in Elderly with Acute Myocardial Infarction Investigators. Effects of angiotensin-converting enzyme inhibition with perindopril on left ventricular remodeling and clinical outcome: results of the randomized Perindopril and Remodeling in Elderly with Acute Myocardial Infarction (PREAMI) Study. Arch Intern Med. 2006;166(6):659-666. 
31. PROGRESS Collaborative Group. Randomised trial of a perindoprilbased blood-pressure-lowering regimen among 6,105 individuals with previous stroke or transient ischaemic attack. Lancet. 2001;358: 1033-1041.

32. Tumanan-Mendoza BA, Dans AL, Villacin LL, et al. Dechallenge and rechallenge method showed different incidences of cough among four ACE-Is. J Clinic Epidemiol. 2007;60(6):547-553.

33. Yesil S, Yesil M, Bayata S, Postaci N. ACE inhibitors and cough. Angiology. 1994;45(9):805-808.

34. Vítovec J, Spinar J. First-dose hypotension after angiotensin-converting enzyme (ACE) inhibitors in chronic heart failure: a comparison of enalapril and perindopril. Slovak Investigator Group. Eur J Heart Fail. 2000;2(3):299-304.

35. Reid JL, MacFadyen RJ, Squire IB, Lees KR. Blood pressure response to the first dose of angiotensin-converting enzyme inhibitors in congestive heart failure. Am J Cardiol. 1993;71(17):57E-60E.

36. Lau CP, Tse HF, $\mathrm{Ng} \mathrm{W}$, et al. Comparison of perindopril versus captopril for treatment of acute myocardial infarction. Am J Cardiol. 2002;89(2): $150-154$.
37. Nedogoda SV, Ledyaeva AA, Chumachok EV, et al. Randomized trial of perindopril, enalapril, losartan and telmisartan in overweight or obese patients with hypertension. Clin Drug Investig. 2013;33(8):553-561.

38. Roman MJ, Devereux RB, Kizer JR, et al. Central pressure more strongly relates to vascular disease and outcome than does brachial pressure: the Strong Heart Study. Hypertension. 2007;50(1):197-203.

39. Verdecchia P. Prognostic value of ambulatory blood pressure: current evidence and clinical implications. Hypertension. 2000;35(3): 844-851.

40. Makani H, Bangalore S, Supariwala A, Romero J, Argulian E, Messerli FH. Antihypertensive efficacy of angiotensin receptor blockers as monotherapy as evaluated by ambulatory blood pressure monitoring: a meta-analysis. Eur Heart J. 2014;35(26):1732-1742.

41. Patel A, ADVANCE Collaborative Group, MacMahon S, et al. Effects of a fixed combination of perindopril and indapamide on macrovascular and microvascular outcomes in patients with type 2 diabetes mellitus (the ADVANCE trial): a randomised controlled trial. Lancet. 2007;370(9590):829-840. 


\section{Authors' reply}

\author{
Ji-Guang Wang' \\ Eduardo Pimenta ${ }^{2}$ \\ Helmut Schumacher ${ }^{2}$ \\ Frank Chwallek ${ }^{2}$
}

'Centre for Epidemiological Studies and Clinical Trials, The Shanghai Institute of Hypertension, Department of Hypertension, Ruijin Hospital, Shanghai Jiaotong University School of Medicine, Shanghai, People's Republic of China; ${ }^{2}$ Boehringer Ingelheim Pharma GmbH \& Co KG, Ingelheim am Rhein, Germany

Correspondence: ji-Guang Wang

The Shanghai Institute of Hypertension, Ruijin 2nd Road 197,

Shanghai 200025, People's Republic of China

Tel +862164370045

Fax +862164662193

Email jiguangwang@aim.com

\section{Dear editor}

In response to the Letter to the editor by DiNicolantonio and O'Keefe we would first like to compliment the authors for their evidentially great efforts to retrieve and select data in support of arguments against the results of our comparative review of controlled, randomized trials with either telmisartan or perindopril.

Indeed, inhibition of the renin-angiotensin aldosterone system (RAAS) with angiotensin-converting enzyme inhibitors (ACEIs) and angiotensin-receptor blockers (ARBs) plays a central role in modern antihypertensive treatment and is also part of modern cardiovascular protection therapy. The mode of action of both drug classes is based on the inhibition of angiotensin II signaling at different stages of the reninangiotensin pathway.

In their letter, DiNicolantonio and O'Keefe conclude that ACEIs but not ARBs should be considered as first-line antihypertensive drugs. This statement calls for further discussion as it ignores the overwhelming evidence for ARBs in the treatment of hypertension, including head-to-head trials against ACEIs, ${ }^{1}$ which have also been acknowledged in hypertension guidelines worldwide. ${ }^{2-4}$ The ARB telmisartan, known to have the longest plasma half-life within the ARB class, ${ }^{5}$ holds an extensive track record of clinical evidence in this regard. In a head-to-head comparison, telmisartan has been shown to have better blood pressure lowering efficacy than perindopril, ${ }^{6}$ which may be explained by the shorter half-life of the latter drug. ${ }^{7}$ Taking into account the importance of treatment adherence in hypertension therapy, ${ }^{4}$ the excellent tolerability and safety profile of ARBs in general-and especially of telmisartan-comprises an important advantage in favor of ARBs when compared with ACEIs and other antihypertensive drug classes.,
We agree with DiNicolantonio and O'Keefe that cough rates differ between studies conducted with several ACEIs. Cough is one of the most frequent reasons for the discontinuation of ACEI therapy. However, discrepancies between reported cough rates are due to differences in study designs rather than to the respective ACEI. The observed rates of cough were much higher in randomized controlled trials ( $9.9 \%$ of patients on an ACEI), in which patients were queried systematically for the symptom, compared with observational cohort studies. ${ }^{1}$

However, we agree with DiNicolantonio and O'Keefe that ACEIs - like ARBs - can be considered for first-line antihypertensive therapy if one would accept the higher risk of side effects associated with ACEI use, perindopril being no exception. ${ }^{1,9}$

Compounds of both drug classes were investigated in large cardiovascular outcome trials and have been shown to be similarly effective in the prevention of cardiovascular events. ${ }^{10,11}$ Nevertheless, comparison of cardiovascular outcome trials with ACEIs or ARBs is impaired, as distinct differences exist between studies. Cardiovascular disease has been investigated at almost every stage of the disease continuum, but differences in patient selection or endpoints remain prominent between studies even when the same stage of cardiovascular disease is the topic of research. ${ }^{12,13}$

For instance, some trials investigated cardiovascular protection in cardiovascular risk patients with uncontrolled hypertension, which itself represents one of the most important cardiovascular risk factors associated with more deaths than other risk factors. A large meta-analysis published in 2002 by Lewington et al in The Lancet showed that every $20 \mathrm{mmHg}$ increase in systolic blood pressure or $10 \mathrm{mmHg}$ increase in diastolic blood pressure is associated with a $>2$-fold increase in stroke mortality and a 2-fold increase in mortality due to ischemic heart disease or other vascular causes. ${ }^{14}$ According to this estimation, a $2 \mathrm{mmHg}$ reduction in systolic blood pressure would be associated with a reduction in the incidence of myocardial infarction and stroke by $7 \%$ and $10 \%$, respectively. ${ }^{14}$ It is therefore difficult to reliably compare results from cardiovascular outcome studies in uncontrolled hypertension aiming to investigate blood pressure lowering effects (eg, Valsartan Antihypertensive Long-term Use Evaluation [VALUE], ${ }^{15}$ Perindopril pROtection aGainst REcurrent Stroke Study [PROGRESS $],{ }^{16}$ Anglo-Scandinavian Cardiac Outcomes Trial-Blood Pressure Lowering Arm [ASCOT-BPLA $]^{17}$ ) with results from trials that investigated cardiovascular outcome in patients with controlled or normal blood pressure (eg, Heart Outcomes Prevention Evaluation [HOPE] ${ }^{18}$ European Trial on Reduction of Cardiac Events With Perindopril in Stable Coronary Artery 
Disease [EUROPA], ${ }^{13,19}$ ONgoing Telmisartan Alone and in combination with Ramipril Global Endpoint Trial [ONTARGET], ${ }^{20}$ Telmisartan Randomized Assessment Study in ACE intolerant [TRANSCEND] ${ }^{21}$ ) as differences in outcome might already be explained by blood pressure reduction or blood pressure variations within study groups.

Other differences comprise the composition of the study population, including the overall risk constellation and presence of specific risk factors, primary or secondary prevention, the type of cardiovascular event (eg, cerebrovascular or cardiac), and the period of time since a cardiovascular event occurred, namely inclusion of patients shortly after an acute stroke (ie, Prevention Regimen for Effectively Avoiding Second Strokes [PRoFESS]) versus inclusion of patients long after the acute phase of a cerebrovascular event (ie, PROGRESS). ${ }^{16,22}$ For example, the TRANSCEND trial investigated the efficacy and safety of telmisartan versus placebo in addition to standard care, and was the first cardiovascular outcome trial with a RAAS inhibitor (ie, ARB) in 5,926 ACEI-intolerant patients initially supposed to be included in the ONTARGET $(n=25,620)$ trial but unable to tolerate treatment with an ACEI. ${ }^{21}$ In addition, differences also exist between the investigated treatment strategies, namely monotherapy or combination therapy, and with regard to the comparator used. Concomitant and standard background medication may have also been grossly different between studies depending on their timing (eg, availability of statins), and may therefore have had a substantial impact on the rates and severity of cardiovascular events affecting study outcomes. All these factors need to be considered when interpreting cardiovascular outcome trial results.

Thus, the interpretation and comparison of outcome trials with RAAS inhibitors should be done with due consideration of the differences that might have influenced the study results. Reliable comparisons between studies are extremely difficult if not impossible.

It is therefore worthwhile to critically examine cardiovascular risk reduction from hypertension trials in contrast to those trials designed to investigate beyond blood pressure effects. Reducing blood pressure in hypertensive patients has been shown to reduce cardiovascular risk. As a result, the US Food and Drug Administration (FDA) recently allowed the extension of the indication of antihypertensive drugs by adding a statement about cardiovascular risk reduction achieved by blood pressure lowering per se in hypertensive individuals. ${ }^{23}$ Indeed, blood pressure dependent cardiovascular risk reduction should be taken into account when designing an outcome trial aiming to show effects beyond blood pressure in cardiovascular protection, with the ONTARGET trial being an example in this regard. ${ }^{20}$ We doubt if effects beyond blood pressure can be independently investigated in hypertensive study populations showing large and clinically relevant blood pressure drops during the conduct of the trial, as has been the case in the ASCOT-BPLA trial where the patient population had a mean baseline systolic blood pressure of $164 \mathrm{mmHg}$ and a diastolic blood pressure of $95 \mathrm{mmHg}$, although $>80 \%$ of patients were already on antihypertensive medication. As a result, the mean blood pressure changes in ASCOT-BPLA were larger than observed in most studies of blood pressure lowering therapy with reductions of 27.5/17.7 and 25.7/15.6 (systolic/diastolic) $\mathrm{mmHg}$ for the amlodipine and atenolol groups, respectively. ${ }^{17,24}$ In light of the impressive blood pressure change, the interpretation of distinct beyond blood pressure effects is difficult as they cannot be separated from those achieved by blood pressure reduction alone.

In a post hoc analysis, ${ }^{24}$ researchers attempted to calculate at least the risk reductions for several endpoints in ASCOT in association with the observed average blood pressure differences of about $3 / 2 \mathrm{mmHg}$ with reference to prospective observational studies and the most recent pooled analysis of clinical trials reported by the Blood Pressure Lowering Treatment Trialists' Collaboration. ${ }^{25,26}$ The results of the analysis suggest that "these differences in blood pressure might explain, approximately, a 4\%-8\% reduction in coronary outcome and an 8\%-14\% difference in strokes". ${ }^{24}$ For stroke and all cardiovascular events, reductions in systolic blood pressure could contribute to approximately half of the benefits of amlodipine-based treatment.

Moreover, in ASCOT-BPLA perindopril was added not earlier than 6 weeks after initiation of amlodipine treatment, and throughout the trial only a mean of $50 \%$ were taking perindopril in addition to amlodipine treatment, ${ }^{24}$ which cast doubt on whether the positive effects of combination therapy with amlodipine could be explained by add-on treatment with perindopril alone.

However, it is an undisputed fact that the best evidence comes from large clinical outcome trials. HOPE ${ }^{18}$ and ONTARGET $^{20}$ are among the most important cardiovascular outcome trials in their respective drug classes investigating beyond blood pressure effects in terms of prevention of cardiovascular events such as myocardial infarction or stroke. Both trials were designed to include normotensive or blood pressure controlled patients, and are distinctly different to studies investigating blood pressure lowering effects in hypertensive patients.

The pivotal ONTARGET trial showed telmisartan to be similarly effective to ramipril in reducing the primary composite (4-fold) endpoint of cardiovascular death, non-fatal 
myocardial infarction, non-fatal stroke, and hospitalization for congestive heart failure as well as the key secondary 3-fold endpoint (same as 4-fold without hospitalization for congestive heart failure). The ONTARGET results comprise a body of evidence demonstrating that telmisartan reduces cardiovascular events in patients at high risk for its occurrence. The incidence of the primary endpoint was $16.7 \%$ and $16.5 \%$ in the telmisartan and ramipril groups, respectively; the hazard ratio for telmisartan versus ramipril was 1.01 (97.5\% confidence interval [CI $0.93-1.10, P$ [non-inferiority $]=0.0019$ at a margin of 1.13). Telmisartan was also found to be similarly effective to ramipril in the pre-specified secondary endpoint of cardiovascular death, non-fatal myocardial infarction, and non-fatal stroke (hazard ratio of 0.99 [97.5\% CI 0.90-1.08], $P$ [non-inferiority $]=0.0004),{ }^{20}$ the primary endpoint in the reference study HOPE, which had investigated the effect of ramipril versus placebo. ${ }^{18}$

Consistent with ONTARGET, the primary endpoint in TRANSCEND was the composite 4-fold endpoint and the key secondary endpoint was again the composite 3-fold endpoint (HOPE endpoint). ${ }^{21}$ For the composite 4-fold primary endpoint, TRANSCEND did not demonstrate superiority of telmisartan over placebo given in addition to standard care ( $15.7 \%$ for telmisartan versus $17.0 \%$ for placebo), resulting in a hazard ratio of telmisartan versus placebo of $0.92(95 \% \mathrm{CI}$ $0.81,1.05 ; P=0.22)$. The analysis of the key secondary 3-fold (primary endpoint in HOPE) composite endpoint in TRANSCEND demonstrated that the incidence of myocardial infarction, stroke, and cardiovascular death was significantly lower in the telmisartan group $(13.0 \%)$ than in the placebo group (14.8\%); the hazard ratio for this comparison was 0.87 (95\% CI 0.76, 1.00; $P=0.048){ }^{21}$

Health authorities worldwide including the US FDA ${ }^{23}$ and European Medicine Agency (EMA) ${ }^{27}$ assessed the data on telmisartan in the prevention of cardiovascular events such as myocardial infarction and stroke in patients at increased risk of such events, and granted telmisartan an indication for the prevention of such events. The clinical evidence on perindopril in beyond blood pressure cardiovascular protection has also been assessed by health authorities, eg, the Committee for Medicinal Products for Human Use (CHMP) of the EMA, based on the results of the EUROPA study. ${ }^{28}$ The CHMP assessment led to an indication for perindopril limited to the reduction of risk of cardiac events in patients with a history of myocardial infarction and/or revascularization, which is different from the broad indication of telmisartan in cardiovascular protection based on the results of the ONTARGET trial program reflecting the differences in the clinical evidence on cardiovascular protection associated with these two compounds..$^{27,28}$

To our belief the most convincing evidence regarding cardiovascular protection beyond blood pressure reduction with an ACEI is owned by ramipril, particularly in regard to the HOPE trial where ramipril was more effective than placebo in preventing major cardiovascular events in high-risk patients without hypertension or those whose hypertension was controlled with other treatments (standard therapy). ${ }^{18}$ The HOPE study provided evidence of the effectiveness of the ACEI ramipril as part of a multifactorial therapeutic approach in preventing cardiovascular death, acute myocardial infarction, and stroke in patients at high cardiovascular risk, and additionally demonstrated significantly better outcomes in secondary endpoints such as revascularization procedures, and hospitalization for heart failure or type 2 diabetes. Ramipril reduced the cardiovascular risk in these patients by approximately $20 \%$ compared with placebo, suggesting a RAAS modifying effect that may exert direct actions on blood vessels beyond their hemodynamic effects. Perindopril, nonetheless, has a large body of clinical data as well, and could be seen as a possible alternative ACEI to ramipril.

Telmisartan is the first ARB which has been proven to provide cardiovascular protection comparable to an ACEI. The ONTARGET trial program represents the largest cardiovascular outcome trial program conducted with an ARB and builds on the evidence provided by the HOPE trial. ${ }^{18}$ It comprises the ONTARGET trial and the simultaneously initiated TRANSCEND trial and was designed and conducted by international experts under the lead of the former principal investigator of HOPE. ${ }^{20,21}$

One additional important aspect to consider when interpreting ACEI and ARB outcome trials refers to data obtained from different patient populations with different baseline risks separated by almost a decade of time, during which the standards of therapy greatly improved as indicated in the different background medications, eg, in $\mathrm{HOPE}^{18}$ and EUROPA $^{13}$ as compared to TRANSCEND ${ }^{21}$ and ONTARGET. ${ }^{20}$ Although entry criteria of the ONTARGET trial program were similar to those of the HOPE trial, patients enrolled were nevertheless different in their individual cardiovascular risk profile and relevant medical history. Patients selected for the placebo-controlled TRANSCEND trial had a lower baseline risk and on entry were treated with more evidence-based co-medications such as statins and antiplatelets which have been associated with outcome improvement in the 8 years since the HOPE trial was conducted. Patients in the ONTARGET study program, in turn, had a considerably 
greater prevalence of cardiovascular protective medication intake, including statins and $\beta$-blockers, compared with those in the HOPE trial. ${ }^{21}$ Moreover, it is important to note that the investigators for ONTARGET/TRANSCEND chose a different primary composite endpoint than those for the HOPE trial, as hospitalization for heart failure was added.

Although clinical data might be interpreted in different ways, according to diverse criteria, in particular those that we have already outlined in this response, we believe that for an appropriate and sound scientific discussion and translation of benefit to clinical practice, we need to use the criteria ensuring the highest strength of recommendation. For this reason we disagree with the line of argumentation by DiNicolantonio and O'Keefe, as - in our opinion - both authors repeatedly tried to compare data from trials with distinct differences when creating their arguments by comparing, for example:

- evidence from large outcome trials with small clinical studies, even with exploratory studies, which at best can be regarded as hypothesis generating;

- studies in untreated hypertensive patients with studies designed to investigate effects in normotensive and controlled hypertensive patients which go beyond-bloodpressure reduction;

- study results in hypertensive and normotensive patients from trials with different cut-offs for hypertension, eg, EUROPA $(160 / 95 \mathrm{mmHg})^{13,19}$ and ASCOT-BPLA $(160 / 100 \mathrm{mmHg}$ and $140 / 90 \mathrm{mmHg}$ in untreated and treated patients, respectively) $)^{17}$ versus telmisartan outcome trials $(140 / 90 \mathrm{mmHg}){ }^{20-22}$

- blood pressure measurements collected using different methods (manual versus ambulatory blood pressure monitoring), regardless of which measurement was defined by the protocol as the reference method (even sub studies of small sub populations from the investigated total study population, eg, in ONTARGET ${ }^{20}$ were used for such comparisons);

- results from studies with combination therapy with those from studies with active single treatment;

- primary and key secondary endpoints with other endpoints of studies that may have provided supportive information, but - in contrast to the primary and key secondary endpoints - without the statistical power needed to draw robust scientific conclusions;

- numerical differences of study results, eg, regarding renal endpoints, without mentioning that the difference was of no statistical significance and not supported by any other endpoint (change of serum creatinine and urinary albumin excretion in the Diabetics Exposed to Telmisartan and Enalapril Study [DETAIL]), resulting in a statement being in conflict with the DETAIL investigators' opinion, who conclude that their results were

consistent with emerging data that support the clinical equivalence of ARBs and ACEIs in various conditions associated with high cardiovascular risk. ${ }^{29}$

In summary, we conclude that the evidence for the ARB telmisartan has been clearly established in the treatment of hypertension as well as in the prevention of cardiovascular events. The trial program consisting of ONTARGET and TRANSCEND provided the solid and conclusive scientific answers regarding the use of an ARB in cardiovascular protection and terminated speculation on whether an $A R B$ could provide cardiovascular protection comparable to the gold-standard ACEI ramipril. Based on the ONTARGET trial program, telmisartan has been granted a broad blood pressure independent cardiovascular protection indication in most countries, which is also acknowledged by recent treatment guidelines. A comparably broad indication has not been granted for perindopril, and it is not mentioned in treatment guidelines to the same extent as telmisartan. Nevertheless, perindopril represents a well investigated ACEI that provides good efficacy as an antihypertensive agent as well as cardiac protection in some specific patient populations.

\section{Disclosure}

Dr Wang has received consulting fees or honoraria and support for travel from Boehringer Ingelheim and payment for lectures, including service on speakers' bureaus from Merck, Sharpe and Dohme, Novartis, Omron, Pfizer, Servier, and Takeda. Dr Chwallek and Dr Schumacher are employees of Boehringer Ingelheim. Dr Pimenta was an employee of Boehringer Ingelheim at the time of the study.

\section{References}

1. Matchar DB, McCrory DC, Orlando LA, et al. Systematic review: comparative effectiveness of angiotensin-converting enzyme inhibitors and angiotensin II receptor blockers for treating essential hypertension. Ann Intern Med. 2008;148(1):16-29.

2. Mancia G, Fagard R, Narkiewicz K, et al. 2013 ESH/ESC Guidelines for the management of arterial hypertension: the Task Force for the management of arterial hypertension of the European Society of Hypertension (ESH) and of the European Society of Cardiology (ESC). J Hypertens. 2013;31(7):1281-1357.

3. National Institute for Health and Care Excellence [homepage on the Internet]. Hypertension: Clinical management of primary hypertension in adults; 2011. Available from: http://www.nice.org.uk/guidance/CG127/ chapter/Introduction. Accessed July 25, 2014. 
4. López-Jaramillo P, Sánchez RA, Diaz M, et al. Latin American consensus on hypertension in patients with diabetes type 2 and metabolic syndrome. J Hypertens. 2013;31(2):223-238.

5. Michel MC, Foster C, Brunner HR, Liu L. A systematic comparison of the properties of clinically used angiotensin II type 1 receptor antagonists. Pharmacol Rev. 2013;65(2):809-848.

6. Ragot S, Ezzaher A, Meunier A, Poterre M, Bourkaib R, Herpin D. Comparison of trough effect of telmisartan vs perindopril using self blood pressure measurement: EVERESTE study. J Hum Hypertens. 2002;16(12):865-873.

7. Heads of Medicine Agencies [homepage on the Internet]. Coveram ${ }^{\circledR}$ (perindopril arginine/amlodipine besylate) SPC. Available from: http:// mri.medagencies.org/Human/Product/Details/10968. Accessed July 25, 2014.

8. Costa FV, Degli Esposti L, Cerra C, Veronesi C, Buda S. Trends in prescription and determinants of persistence to antihypertensive therapy: the PAPEETE study. High Blood Press Cardiovasc Prev. 2009;16(4): $167-176$.

9. Bangalore S, Kumar S, Messerli FH. Angiotensin-converting enzyme inhibitor associated cough: deceptive information from the Physicians' Desk Reference. Am J Med. 2010;123(11): 1016-1030.

10. Reboldi G, Angeli F, Cavallini C, Gentile G, Mancia G, Verdecchia P. Comparison between angiotensin-converting enzyme inhibitors and angiotensin receptor blockers on the risk of myocardial infarction, stroke and death: a meta-analysis. $J$ Hypertens. 2008;26(7): 1282-1289.

11. McAlister FA; Renin Angiotensin System Modulator Meta-Analysis Investigators. Angiotensin-converting enzyme inhibitors or angiotensin receptor blockers are beneficial in normotensive atherosclerotic patients: a collaborative meta-analysis of randomized trials. Eur Heart J. 2012;33(4):505-514.

12. Gerstein HC, Mann JF, Yi Q, et al. Albuminuria and risk of cardiovascular events, death, and heart failure in diabetic and nondiabetic individuals. JAMA. 2001;286(4):421-426.

13. Fox KM; EURopean trial On reduction of cardiac events with Perindopril in stable coronary Artery disease Investigators. Efficacy of perindopril in reduction of cardiovascular events among patients with stable coronary artery disease: randomised, double-blind, placebo-controlled, multicentre trial (the EUROPA study). Lancet. 2003;362(9386):782-788.

14. Lewington S, Clarke R, Qizilbash N, Peto R, Collins R; Prospective Studies Collaboration. Age-specific relevance of usual blood pressure to vascular mortality: a meta-analysis of individual data for one million adults in 61 prospective studies. Lancet. 2002;360(9349): 1903-1913.

15. Julius S, Kjeldsen SE, Weber M, et al. Outcomes in hypertensive patients at high cardiovascular risk treated with regimens based on valsartan or amlodipine: the VALUE randomised trial. Lancet. 2004;363(9426): 2022-2031.

16. PROGRESS Collaborative Group. Randomised trial of a perindopril-based blood-pressure-lowering regimen among 6,105 individuals with previous stroke or transient ischaemic attack. Lancet. 2001;358(9287):1033-1041. Erratum in: Lancet. 2002;359(9323):2120. Lancet. 2001;358(9292):1556.
17. Dahlöf B, Sever PS, Poulter NR, et al. Prevention of cardiovascular events with an antihypertensive regimen of amlodipine adding perindopril as required versus atenolol adding bendroflumethiazide as required, in the Anglo-Scandinavian Cardiac Outcomes Trial-Blood Pressure Lowering Arm (ASCOT-BPLA): a multicentre randomised controlled trial. Lancet. 2005;366(9489):895-906.

18. Yusuf S, Sleight P, Pogue J, et al. Effects of an angiotensin-converting-enzyme inhibitor, ramipril, on cardiovascular events in highrisk patients. The Heart Outcomes Prevention Evaluation Study Investigators. $N$ Engl J Med. 2000;342(3):145-153. Erratum in: $N$ Engl J Med. 2000;342(10):748. 2000;342(18):1376.

19. Gomma AH, Fox KM. The EUROPA trial: design, baseline demography and status of the substudies. Cardiovasc Drugs Ther. 2001;15(2): 169-179.

20. ONTARGET Investigators; Yusuf S, Teo KK, et al. Telmisartan, ramipril, or both in patients at high risk for vascular events. $N$ Engl J Med. 2008;358(15):1547-1559.

21. Telmisartan Randomised AssessmeNt Study in ACE iNtolerant subjects with cardiovascular Disease (TRANSCEND) Investigators; Yusuf S, Teo K, et al. Effects of the angiotensin-receptor blocker telmisartan on cardiovascular events in high-risk patients intolerant to angiotensinconverting enzyme inhibitors: a randomised controlled trial. Lancet. 2008;372(9644):1174-1183.

22. Yusuf S, Diener HC, Sacco RL, et al. Telmisartan to prevent recurrent stroke and cardiovascular events. N Engl J Med. 2008;359(12): 1225-1237.

23. US Food and Drug Administration [homepage on the Internet]. US Department of Health and Human Services; Center for Drug Evaluation and Research (CDER). Guidance for industry: hypertension indication: drug labeling for cardiovascular outcome claims; 2011. Available from: http://www.fda.gov/downloads/Drugs/.../Guidances/ucm075072.pdf. Accessed July 25, 2014.

24. Sever PS. The Anglo-Scandinavian Cardiac Outcomes Trial: implications and further outcomes. Hypertension. 2012;60(2):248-259.

25. Neal B, MacMahon S, Chapman N; Blood Pressure Lowering Treatment Trialists' Collaboration. Effects of ACE inhibitors, calcium antagonists, and other blood-pressure-lowering drugs: results of prospectively designed overviews of randomised trials. Lancet. 2000;356(9246): 1955-1964.

26. Turnbull F; Blood Pressure Lowering Treatment Trialists' Collaboration. Effects of different blood-pressure-lowering regimens on major cardiovascular events: results of prospectively-designed overviews of randomised trials. Lancet. 2003;362(9395):1527-1535.

27. European Medicines Agency [homepage on the Internet]. Assessment report for Micardis (telmisartan). European Medicines Agency; 2009. Available from: http://www.ema.europa.eu/docs/en_GB/document_ library/EPAR___Assessment_Report_-_Variation/human/000209/ WC500073444.pdf. Accessed July 25, 2014.

28. European Medicines Agency [homepage on the Internet]. Committee for Medicinal Products for Human Use opinion following an Article 6 (12) referral: perindopril; 2005. Available from: http://www.ema.europa. eu/ema/index.jsp?curl=pages/medicines/human/referrals/Coversyl/ human_referral_000138.jsp\&mid=WC0b01ac05805c516f. Accessed July 25, 2014.

29. Barnett AH, Bain SC, Bouter P, et al. Angiotensin-receptor blockade versus converting-enzyme inhibition in type 2 diabetes and nephropathy. N Engl J Med. 2004;351(19):1952-1961.
Vascular Health and Risk Management

\section{Publish your work in this journal}

Vascular Health and Risk Management is an international, peerreviewed journal of therapeutics and risk management, focusing on concise rapid reporting of clinical studies on the processes involved in the maintenance of vascular health; the monitoring, prevention and treatment of vascular disease and its sequelae; and the involvement of
Dovepress

metabolic disorders, particularly diabetes. This journal is indexed on PubMed Central and MedLine. The manuscript management system is completely online and includes a very quick and fair peer-review system, which is all easy to use. Visit http://www.dovepress.com/ testimonials.php to read real quotes from published authors. 